\title{
BMJ Open Incidence and immediate consequences of electrical shocks among Danish electricians: a cohort study
}

\author{
Karin Biering (D) , Anette Kærgaard, Ole Carstensen, Kent Jacob Nielsen
}

To cite: Biering K, Kærgaard A, Carstensen 0 , et al. Incidence and immediate consequences of electrical shocks among Danish electricians: a cohort study. BMJ Open 2021;11:e046584. doi:10.1136/ bmjopen-2020-046584

- Prepublication history and additional supplemental material for this paper are available online. To view these files, please visit the journal online. (http://dx.doi.org/10.1136/ bmjopen-2020-046584).

Received 04 November 2020 Accepted 27 July 2021

Check for updates

(C) Author(s) (or their employer(s)) 2021. Re-use permitted under CC BY-NC. No commercial re-use. See rights and permissions. Published by BMJ.

Department of Occupational Medicine - University Research Clinic - Danish Ramazzini Centre, Herning Regional Hospital, Herning, Denmark

Correspondence to

Mrs Karin Biering; karbie@rm.dk

\section{ABSTRACT}

Objectives The health-related consequences of electrical shocks are mostly studied in patients from selected cohorts in hospital burn units, by making internal comparisons of subgroups, but without comparing them to unexposed individuals, or considering information regarding the preinjury health of the injured persons. Often, little is known about the details of the electrical shocks. Our purpose was to do a longitudinal study of Danish electrical workers, to monitor exposure to electrical shocks weekly over a 6-month period and to determine whether these shocks have short-term, health-related consequences.

Design Prospective cohort study with weekly measurements.

Setting Members of the Danish Union of Electricians. Participants Of the 22284 invited, 6960 electricians $(31 \%)$ participated in the baseline data collection, and the participation rate in the weekly follow-up ranged from $61 \%$ to $81 \%$ during the 6 month follow-up.

Primary and secondary outcome measures The primary outcome measure was an electrical shock and secondary outcomes were the immediate health-related consequences of the shocks.

Results A total of 2356 electrical shocks were reported by $1612(23 \%)$ of the participants during the 26 -week follow-up. Alternating current and voltage below $1000 \mathrm{~V}$ were the most common forms of electricity. In most cases, the fingers/hands were the entry and exit points, but many were unable to specify the exit point. The participants categorised $73 \%$ of the electrical shocks as 'not at all severe', and most of the shocks did not cause any immediate physical damage. However, flashbacks were more common than physical consequences. Only a few of the participants contacted health services following an electrical shock, and even fewer were absent from work. Conclusion Nearly one-fourth of Danish electricians experienced one or more electrical shocks during a 26week period, but most of the shocks are not perceived as severe, and have only limited immediate consequences.

\section{INTRODUCTION}

Electrical injuries occur in homes, in public and at all types of workplaces. Despite regulations and safety precautions, both children and adults are injured, although most injuries happen to young men. 'Electrical workers, such as electricians and technicians working

\section{STRENGTHS AND LIMITATIONS OF THIS STUDY \\ $\Rightarrow$ First prospective cohort study for collecting informa- tion on electrical shocks among Danish electricians. \\ $\Rightarrow$ The prospective design provides information about health before shocks in future studies. \\ $\Rightarrow$ Low participation rate carries the risk of selection bias. \\ $\Rightarrow$ Possibility of long-term follow-up in health registries.}

with electrical installations, are a professional group especially at risk of electrical injuries. When they are injured by electrical shocks, it is rarely a result of ignorance, but more often due to miscommunication, working without turning off the electrical current or simple sloppiness, perhaps because of time pressure. $^{2}$

Existing knowledge about the frequency of electrical injuries is limited. In Denmark, as in most other countries, non-fatal electrical injuries are not systematically registered, and thus their incidence is unknown. For instance, electrical injuries in Denmark were registered with The Danish Safety Technology Authority until 2010, but only if the accident was caused by a technical fault in the equipment. ${ }^{3}$ Hospitals are another source of information on electrical injuries, where electrical injuries have their own International Classification of Diseases 10th Revision code, which has been increasingly used in Danish hospitals over the last decade. Furthermore, work-related electrical injuries are registered by The Danish Working Environment Authorities (DWEA). All types of injuries may be registered, but registration is mandatory if the injury results in sick leave for at least the day following the day of the injury. ${ }^{4}$ However, it is well-documented that only approximately $50 \%$ of occupational injuries are actually reported to DWEA. ${ }^{5}$ Thus, under-reporting is likely, and less severe exposure to electrical current is not registered. ${ }^{6}$ There is no comprehensive overview of the incidence of 
electrical injuries' in Denmark, and this probably applies to other countries as well.

The consequences of exposure to electrical current range from a momentary scare and temporary pain, to severe burns and tissue damage, to death, although fatal electrical injuries are rare in Denmark, with an average of fewer than two per year in a population of 5.8 million. ${ }^{3}$ A range of case studies and studies of groups of patients who have suffered an electrical injury suggest a variety of mental and physical symptoms. Some of these are common physical symptoms, such as headaches, muscle pain, sensory disturbances, but mental symptoms, such as cognitive problems, anxiety and depression are also reported. ${ }^{7-9}$

The purpose of this project was to collect data regarding participants' health previous to their reported electrical shocks, to facilitate unbiased comparisons within and between participants' health and to establish a basis for long-term follow-up in future studies.

The aim of this study was to prospectively monitor and describe electrical shocks and their immediate healthrelated consequences in a cohort of Danish electricians.

\section{MATERIALS AND METHODS}

This was a 6-month prospective cohort study of Danish electricians, with weekly questionnaires.

\section{Setting and data collection}

The Danish Union of Electricians has approximately 28000 members, and organises electricians, technicians, apprentices and others electrical workers in Denmark. It is estimated that $67 \%$ of all Danish electricians are members. The data collection was conducted from October 2019 to May 2020 and had two parts: a baseline survey and 26 weeks of short, weekly, follow-up questionnaires. The survey content is described later in detail.

Before inviting union members to participate in the cohort, an information campaign about the project was presented to the members through the union's print magazine, webpage, Facebook pages, newsletters, and at member meetings and meetings of work environment representatives. This was done to ensure a high participation rate. To motivate participation, during the enrolment phase and each week of follow-up, we held a lottery for cinema-ticket vouchers for respondents, and three of the eleven local union branches held a lottery for a hotel stay for those who participated in the entire follow-up period.

Invitations to participate in the cohort were emailed to all members of the union who had registered an email address. The information campaign continued in the weeks after the invitations were sent, and along with updates on the project throughout the follow-up period, to motivate the members to respond and to continue responding during the follow-up period. After the initial invitation email, we emailed up to three reminders to the members, approximately 1 week apart. Furthermore, the union phoned a large number of non-responders, to motivate them to participate.

\section{Procedures}

Inclusion in the cohort required agreement to participate in the follow-up period, during which participants received a text message with a link to a short, web-based questionnaire each Wednesday, for 26 consecutive weeks. A small group of participants received the weekly link by email instead of text message, primarily persons working offshore, where phone connections were not stable. The links to the weekly questionnaires remained open to responses throughout the data collection period, but responses were placed according to their actual response date, and shocks reported more than 14 days after the incident were excluded (primarily during the first week of the data collection, some reported shocks from several years before). If a participant did not respond to text message within 24 hours, they received a reminder. If a participant did not respond for two consecutive weeks, the researchers sent an email with a request to respond and continue participating in the study. If the participants did not respond after this, their contact information was given to their local union branch, where local representatives tried to phone them and motivate them to continue participating. Not all non-responders were phoned, owning to capacity of personnel in the union branches, and some were phoned in vain, or a message was left on their answering service. This telephone reminder procedure was unsystematic, because of variations in the resources of the union branches, and over time.

Data were collected and managed using REDCap electronic data capture tools, hosted by Aarhus University. ${ }^{10}$

\section{Content of the baseline and weekly follow-up web-based surveys}

The baseline survey consisted of questions about the participants, their health and their perception of their health. This included questions about symptoms and recent exposure to electrical shocks, as in the weekly questionnaire (online supplemental file 1). Questions about recent exposure to electrical shock were designed so the participants were only presented with questions that were relevant to them, based on the answers they gave. Most notably, the participants responded to a range of detailed questions about the characteristics and consequences of a shock only if they reported having experienced an electrical shock.

The weekly follow-up questionnaires included questions on electrical shock exposure, and posed questions on absenteeism, ability to work and single-item versions of the symptom scales used in the baseline survey (online supplemental file 1), regardless of the participant's exposure to electrical shock, to prospectively monitor the participant's health prior to any electrical injury that might eventually occur. 
Table 1 Demographic characteristics of participants $(\mathrm{N}=6960)$ and non-participants $(\mathrm{n}=15324)$

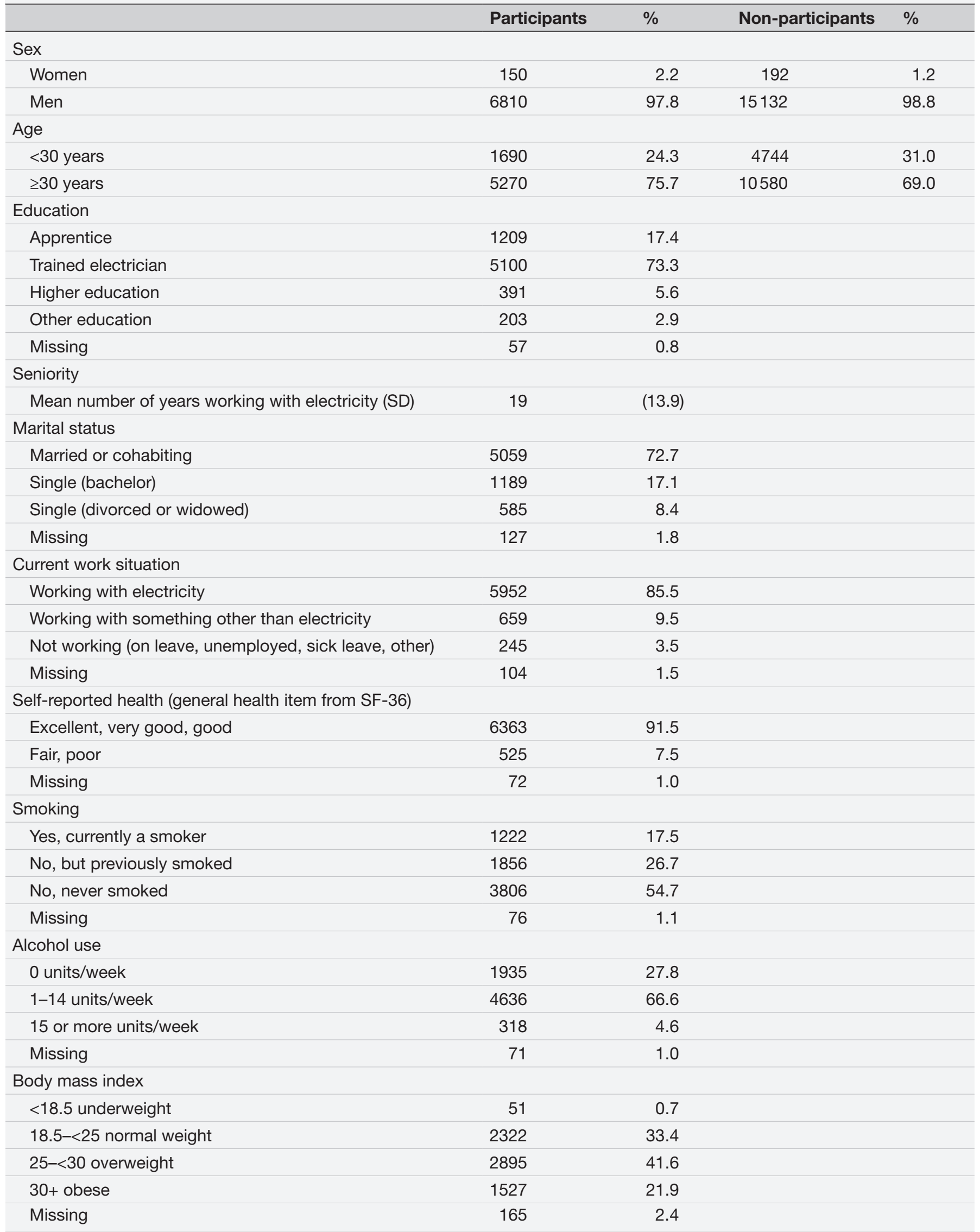




\section{Patient and public involvement statement}

When we designed and planned the project, we involved a steering group of members from the electricians' union and other organisations that addressed electricity and technical safety, to ensure that the participants would be able to understand questionnaires, and that they covered relevant aspects of electrical injuries. We also tested the questionnaire on a small group of electricians before the final version was launched. ${ }^{11-18}$

\section{Linkage of data}

Every person working and living in Denmark has a unique personal identification number, called the CPR number. ${ }^{19}$ The participants consented to the use of their CPR numbers for later follow-up in registries. Each Danish citizen as well as registered migrant workers holds this unique CPR number that provide the possibility to link each person across different registries. This makes it possible to study outcomes after the relatively short follow-up survey. In this study, the CPR number was used to determine participant sex and age.

\section{Analysis}

Data were presented as counts and percentages, including information about missing data. Participants were compared with non-participants with regard to age and sex. Details regarding exposure to electrical shocks and their immediate consequences were described, and participation and proportions of electrical shocks over time were presented graphically. All data management and analysis were conducted in Stata V.16.1

\section{RESULTS}

\section{Participation}

We invited 22284 members of the Danish Union of Electricians to participate, excluding members without an email address, and retired members. Of these, 6960 agreed to participate, but 50 did not complete the baseline questionnaire. Table 1 provides demographic information for respondents compared with non-respondents, and other baseline characteristics. The proportion of women and of persons over 30 was larger among respondents than non-respondents, in line with other population-based studies. Most of the participants were trained electricians, and apprentices were the second largest group. They reported slightly better health than the Danish population in general, and reported lower alcohol use, whereas the smoking habits and body mass index were in line with the Danish male population. ${ }^{20}$

\section{Participation during follow-up}

The weekly response rate declined from $81 \%$ to $62 \%$ during the first 11 weeks of follow-up. After that, the response rate stabilised at approximately $63 \%$ for the rest of the data collection period (figure 1).

\section{Electrical shocks}

During the 26 weeks of follow-up, 2356 electrical shocks were reported with 1133 persons (16.3\%) reporting one shock, 319 persons (4.6\%) reporting two shocks, 97 persons $(1.4 \%)$ reporting three shocks and 63 persons $(0.9 \%)$ reporting four to nine shocks. This indicates that $1612(23 \%)$ of the participants had experienced at least one electrical shock during these 26 weeks.

The shocks (not persons) are presented in detail in the following tables. The vast majority of the shocks were classified as 'not at all severe' by the participants. The type of electricity was most often alternating current and voltage under $1000 \mathrm{~V}$ (table 2A).

During the follow-up period, there was a small decline over time in the reports of the incidence of shocks, and a dip in reporting over Christmas and the new year (around weeks 12-13 of the data collection), because of the holidays (figure 2). In the baseline questionnaire,

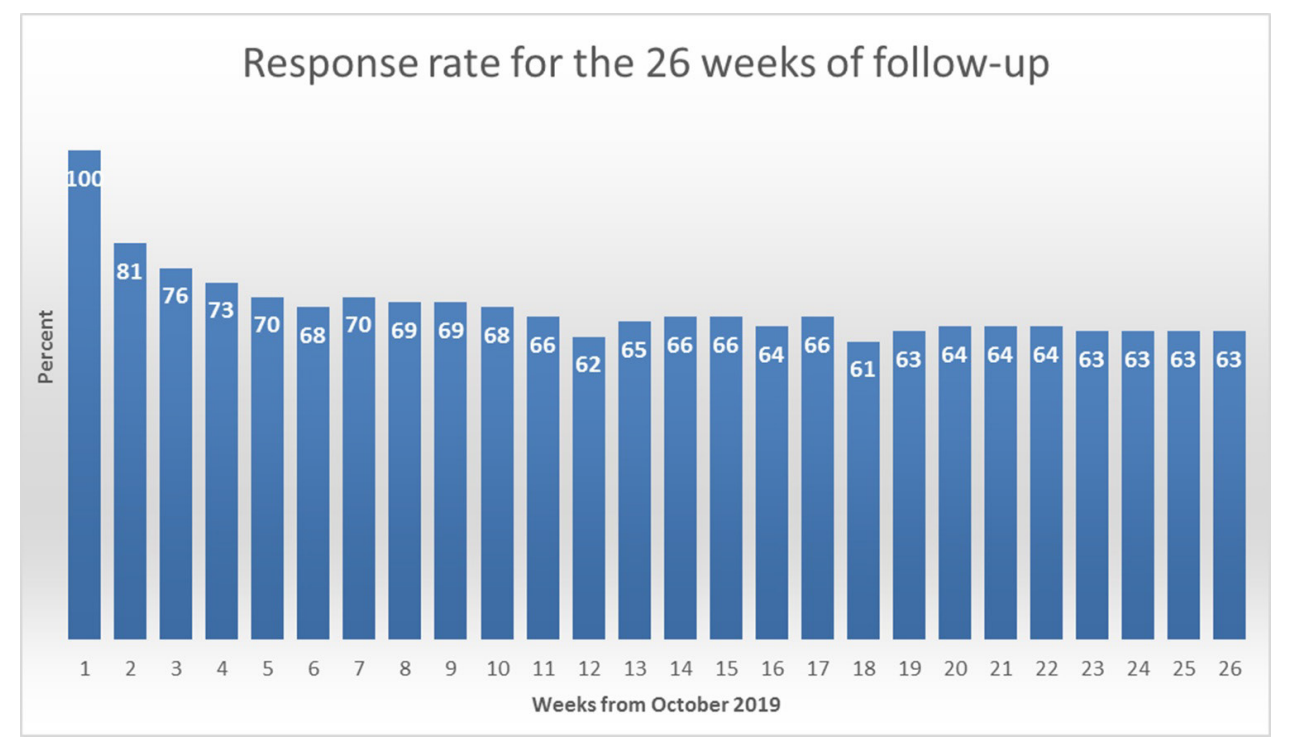

Figure 1 Response rate during the 26 weeks of follow-up. 
Table 2A Description of electrical shocks reported $(\mathrm{N}=2356)$ over 26 weeks by Danish electricians

\begin{tabular}{|c|c|c|}
\hline & $n$ & $\%$ \\
\hline \multicolumn{3}{|c|}{ Number of shocks/person } \\
\hline 1 & 1133 & 48.1 \\
\hline 2 & 638 & 27.1 \\
\hline 3 & 291 & 12.3 \\
\hline $4-9$ & 294 & 12.5 \\
\hline \multicolumn{3}{|l|}{ Type of electricity } \\
\hline Alternating current & 2006 & 85.1 \\
\hline Direct current & 142 & 6.0 \\
\hline Electrical arc & 8 & 0.3 \\
\hline Induction & 27 & 1.2 \\
\hline Static electricity & 102 & 4.3 \\
\hline Unknown & 65 & 2.8 \\
\hline Missing & 6 & 0.3 \\
\hline \multicolumn{3}{|l|}{ Voltage } \\
\hline Under $230 \mathrm{~V}$ & 340 & 14.4 \\
\hline $230 \mathrm{~V}$ & 1455 & 61.8 \\
\hline $400 \mathrm{~V}$ & 62 & 2.6 \\
\hline $400-1000 \mathrm{~V}$ & 16 & 0.7 \\
\hline Over $1000 \mathrm{~V}$ & 22 & 0.9 \\
\hline Unknown & 78 & 3.3 \\
\hline Missing & 383 & 16.3 \\
\hline \multicolumn{3}{|l|}{ Self-reported severity } \\
\hline Not at all severe & 1725 & 73.2 \\
\hline Slightly severe & 534 & 22.7 \\
\hline Somewhat severe & 66 & 2.8 \\
\hline Quite severe & 15 & 0.6 \\
\hline Very severe & 6 & 0.3 \\
\hline Missing & 10 & 0.4 \\
\hline
\end{tabular}

several of the participants reported shocks going back some time, but these were omitted from the data if they happened more than 14 days before the questionnaire was completed.

\section{Immediate consequences}

Most of the shocks had an entry point in a finger, hand or arm. In most cases, the exit point was also a finger, hand or arm, but many reported that the exit point was unknown. Current passing across the body (in most cases, upper extremity to upper extremity) was less frequent than same side exposure, but again, many did not know, equivalent to reporting of the unknown exit points. Exposure on dry skin was more common than on wet/damp skin (table 2B).

Most of the shocks did not cause any immediate injury, direct or indirect. Table 2C shows consequences reported in the same week as the shock. Only 13 shocks were followed by unconsciousness, whereas 49 shocks led to memory loss; these numbers may be a bit higher than reported, as seven and nine persons, respectively, answered 'do not know' to these questions. In 177 cases those who experienced electrical shocks contacted their doctor/went to hospital, and 68 led to an injury-related absence from work. In 252 cases, shocks caused flashbacks; this exceeds the number of shocks that resulted in physical injury (table 2C).

\section{DISCUSSION \\ Key results}

Of the 22284 eligible members of the Danish Union of Electricians, 6960 (31\%) participated in our cohort study, and of these, $61 \%-81 \%$ participated in the 26-week follow-up. During the data collection period, 2356 electrical shocks were experienced by $23.1 \%$ of the participants. Of the participants, 1133 (16.3\% of participants) experienced one shock and 1223 (6.9\% of participants) experienced two to nine shocks. The reporting of shocks declined slightly over time. Most of the shocks were reported as 'not severe'. The most frequent type of electricity was alternating current and a voltage below 1000 $\mathrm{V}$. The most common entry and exit points were fingers, hands and arms, predominantly dry skin. Surprisingly, many electricians could not determine whether they had current passing across the body, $66 \%$ of these because they could not determine the exit point of a shock.

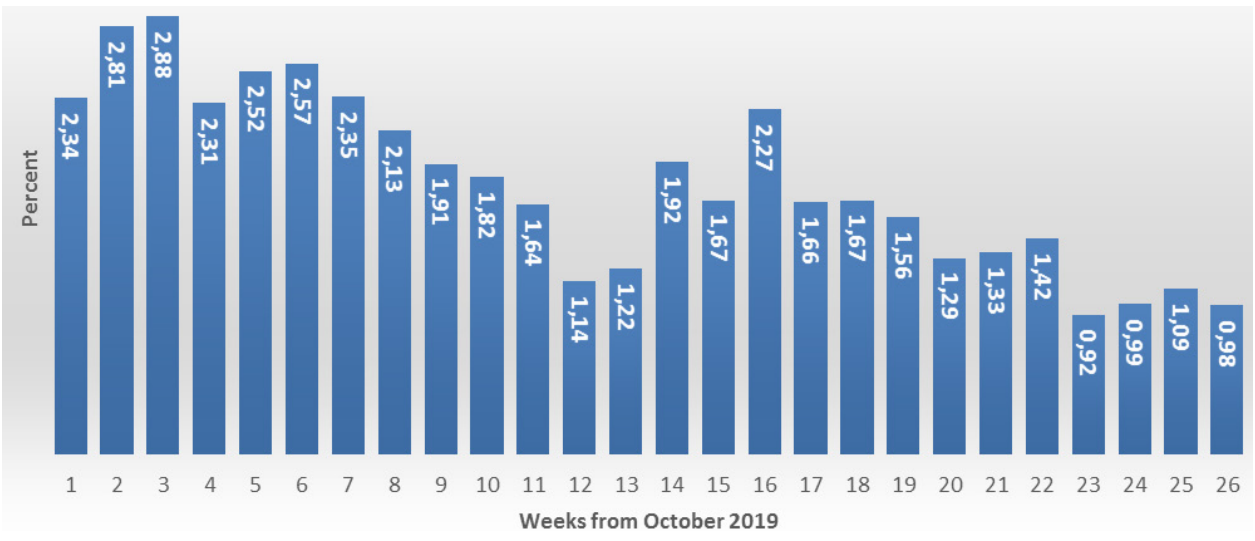

Figure 2 Proportion of participants reporting electrical shocks during the 26 weeks of follow-up. 
Table 2B Description of reported electrical shocks by entry and exit point $(\mathrm{N}=2356)$

\begin{tabular}{|c|c|c|}
\hline & $\mathbf{n}$ & $\%$ \\
\hline \multicolumn{3}{|l|}{ Entry point } \\
\hline Hand/finger & 2116 & 89.8 \\
\hline Arm & 67 & 2.8 \\
\hline Other & 24 & 1.0 \\
\hline Missing* & 149 & \\
\hline \multicolumn{3}{|c|}{ Moistness of entry point } \\
\hline Dry & 1771 & 75.2 \\
\hline Wet/damp & 428 & 18.2 \\
\hline Missing* & 157 & 6.7 \\
\hline \multicolumn{3}{|l|}{ Exit point } \\
\hline Hand/finger & 1077 & 45.7 \\
\hline Arm & 171 & 7.3 \\
\hline Other & 270 & 11.5 \\
\hline Unknown & 689 & 29.2 \\
\hline Missing* & 149 & 6.3 \\
\hline \multicolumn{3}{|c|}{ Moistness of exit point } \\
\hline Dry & 1218 & 51.7 \\
\hline Wet/damp & 281 & 11.9 \\
\hline Missing* & 857 & 36.4 \\
\hline \multicolumn{3}{|c|}{ Current passing across the body } \\
\hline Yes & 249 & 10.6 \\
\hline No & 1106 & 46.9 \\
\hline Unknown & 842 & 35.7 \\
\hline Missing ${ }^{\star}$ & 159 & 6.7 \\
\hline
\end{tabular}

*Those who reported electrical arc, induction or static electricity were not asked these questions, and included in the missing group.

The immediate consequences reported the same week as an electrical shock were also rare. However, $4.7 \%$ resulted in red skin marks, $2.1 \%$ resulted in memory loss and $10.7 \%$ caused flashbacks to various extents. In $7.5 \%$ of cases, healthcare services were contacted, but few shocks resulted in absence from work for more than the same day, and in parallel with this, only a few reported reduced ability to work following a shock.

\section{Limitations}

To the best of our knowledge, the cohort of electrical workers we studied is the first to be monitored for electrical injuries through a prospective design. Despite an intensive campaign to motivate participation, this survey had a relatively low participation rate. This is a possible limitation of the study, especially because the distribution of ages was different among participants and nonparticipants. Attrition during the follow-up phase may also present a problem, as $19 \%$ did not respond to any of the follow-up messages, and up to $40 \%$ of those who responded to the baseline questions stopped answering
Table 2C Immediate consequences of electrical shock (reported in same week as shock) $(\mathrm{N}=2356)$

\begin{tabular}{|c|c|c|}
\hline & $\mathbf{n}$ & $\%$ \\
\hline \multicolumn{3}{|c|}{ Physical injury caused by the shock } \\
\hline Yes: red marks on skin & 110 & 4.7 \\
\hline Yes: burn & 45 & 1.9 \\
\hline Yes: other & 29 & 1.2 \\
\hline No & 2164 & 91.9 \\
\hline Missing & 8 & 0.3 \\
\hline \multicolumn{3}{|c|}{ Other physical injury related to the shock (eg, from falling) } \\
\hline Yes & 34 & 1.4 \\
\hline No & 2315 & 98.3 \\
\hline Missing & 7 & 0.3 \\
\hline \multicolumn{3}{|l|}{ Unconsciousness } \\
\hline Yes & 13 & 0.5 \\
\hline No & 2322 & 98.6 \\
\hline Unknown & 7 & 0.3 \\
\hline Missing & 14 & 0.6 \\
\hline \multicolumn{3}{|l|}{ Memory loss } \\
\hline Yes & 49 & 2.1 \\
\hline No & 2292 & 97.3 \\
\hline Unknown & 9 & 0.4 \\
\hline Missing & 6 & 0.3 \\
\hline \multicolumn{3}{|l|}{ Contacted health services } \\
\hline Yes: outpatient visit & 150 & 6.4 \\
\hline Yes: admitted & 27 & 1.1 \\
\hline No & 2166 & 91.9 \\
\hline Missing & 13 & 0.6 \\
\hline \multicolumn{3}{|l|}{ Absent from work } \\
\hline Yes: the same day & 57 & 2.4 \\
\hline Yes: more than 1 day & 11 & 0.5 \\
\hline No & 2278 & 96.7 \\
\hline Missing & 10 & 0.4 \\
\hline \multicolumn{3}{|l|}{ Self-reported ability to work } \\
\hline Very good & 2167 & 92.0 \\
\hline Good & 151 & 6.4 \\
\hline Average to very poor & 8 & 0.3 \\
\hline Missing & 30 & 1.3 \\
\hline \multicolumn{3}{|l|}{ Flashbacks } \\
\hline Not at all & 2094 & 88.9 \\
\hline To a minor extent & 208 & 8.8 \\
\hline To some extent & 31 & 1.3 \\
\hline In high/very high extent & 13 & 0.6 \\
\hline Missing & 10 & 0.4 \\
\hline
\end{tabular}

during the follow-up phase. However, some participants who stopped answering during the data collection returned later. This intermittent pattern of answering 
is not as prone to bias as attrition is, if the respondents provided answers both before and after an electrical shock. The decline in the number of shocks over time was greater than the attrition, and we could not find an explanation for this. We examined the response pattern for changes related to reporting a shock, but that was not the case. Participation in the study may have increased awareness of the risk of electrical shock, and this may have led to the decrease.

Participation in the study, especially the baseline survey, which included many questions with various types of response categories, required fundamental reading skills. This may have caused persons who had reading difficulties to be under-represented in the cohort as they might give up on answering. On the other hand, all members of the Danish Union for Electricians are trained electricians, technicians or apprentices who should have sufficient reading skills to participate in this sort of study.

\section{Interpretation}

Only a small proportion of the electrical-shock-related injuries prompted participants to contact a healthcare professional. Most previous studies of electrical injuries are based on hospitalised patients, unusually those in specialised burn units. This study describes a heterogeneous group of electrical shocks, and thus the low proportion of extremely severe shocks reported means that it is not comparable to previous studies in other settings. Since, as far as we know, this study is the first to monitor electrical injuries among electricians through a prospective design with repeated measurements, it is not possible to compare this study with previous work. However, a Norwegian retrospective study of electricians estimated an incidence of 7.6 serious electrical injuries per 100 person-years, ${ }^{6}$ which, translated to our design, would result in over 200 serious injuries over 6 months of follow-up. This was not reflected in our findings, in which only 31 shocks were reported as 'quite severe' or 'very severe'. We cannot know whether or not this discrepancy is related to recall bias in the Norwegian study, a different study population, or changes in incidence over time. A retrospective Swedish study of electricians who had experienced at least one electrical shock showed that half of the respondents had experienced an electrical injury at some point in their working life. ${ }^{21}$

\section{Generalisability}

This study may be generalised to other populations of electricians, where the regulations and safety guidelines are in line with the Danish ones. If the participants' risk of electrical shock is consistent with those who did not participate, the incidence and the characteristics of the shocks may be extrapolated to the entire population of Danish electricians. The opportunity to examine the cohort's participants' health before and after an electrical shock may provide results that are generalisable to other contexts, as the participants are compared with themselves before and after an electrical shock, rather than to other populations.

Contributors $\mathrm{KB}, \mathrm{AK}, \mathrm{OC}$ and $\mathrm{KJN}$ designed the study, discussed its results, strengths and limitations, and approved the final version of the manuscript. KJN programmed the REDCap data collection; KB carried out the initial data management and analysis, wrote the first draft of the manuscript and is responsible for the overall content.

Funding This study was supported by the Danish Working Environment Research Fund, grant number 22-2017-09.

Competing interests None declared.

Patient consent for publication Obtained.

Ethics approval The data collection was approved by Central Region on behalf of the Danish Data Protection Agency \#1-16-02-139-19. Approval from the Ethics Committee is exempted in Denmark for questionnaire-based data collection.

Provenance and peer review Not commissioned; externally peer reviewed.

Data availability statement Data are available upon reasonable request. Anonymised data are available from the authors on reasonable request.

Supplemental material This content has been supplied by the author(s). It has not been vetted by BMJ Publishing Group Limited (BMJ) and may not have been peer-reviewed. Any opinions or recommendations discussed are solely those of the author(s) and are not endorsed by BMJ. BMJ disclaims all liability and responsibility arising from any reliance placed on the content. Where the content includes any translated material, BMJ does not warrant the accuracy and reliability of the translations (including but not limited to local regulations, clinical guidelines, terminology, drug names and drug dosages), and is not responsible for any error and/or omissions arising from translation and adaptation or otherwise.

Open access This is an open access article distributed in accordance with the Creative Commons Attribution Non Commercial (CC BY-NC 4.0) license, which permits others to distribute, remix, adapt, build upon this work non-commercially, and license their derivative works on different terms, provided the original work is properly cited, appropriate credit is given, any changes made indicated, and the use is non-commercial. See: http://creativecommons.org/licenses/by-nc/4.0/.

\section{ORCID iDs}

Karin Biering http://orcid.org/0000-0001-7038-9566

Kent Jacob Nielsen http://orcid.org/0000-0002-4643-5697

\section{REFERENCES}

1 Shih JG, Shahrokhi S, Jeschke MG. Review of adult electrical burn injury outcomes worldwide: an analysis of low-voltage vs highvoltage electrical injury. J Burn Care Res 2017;38:e293-8.

2 Thomée S, Jakobsson K. Life-changing or trivial: Electricians' views about electrical accidents. Work 2018;60:573-85.

3 [Statistics of electrical accidents]. Copenhagen: the Danish safety technology authority, 2010.

4 OSH system at national level - Denmark: European Agency for Safety and Health at Work, 2020. Available: https://oshwiki.eu/wiki/OSH_ system_at_national_level_-_Denmark [Accessed 19 Mar 2020].

5 Lander F, Nielsen KJ, Rasmussen K, et al. Patterns of work injuries: cases admitted to emergency room treatment compared to cases reported to the Danish working environment authority during 20032010. Occup Environ Med 2014;71:97-103.

6 Goffeng LO, Veiersted KB, Moian R, et al. [Incidence and prevention of occupational electrical accidents]. Tidsskr Nor Laegeforen 2003;123:2457-8.

7 Andrews CJ, Reisner AD. Neurological and neuropsychological consequences of electrical and lightning shock: review and theories of causation. Neural Regen Res 2017;12:677-86.

8 Biering KV, Kærgaard JM, Carstensen A. Mental disorders following electrical injuries - a register-based, matched cohort study. Occup Environ Med 2020.

9 Duff K, McCaffrey RJ. Electrical injury and lightning injury: a review of their mechanisms and neuropsychological, psychiatric, and neurological sequelae. Neuropsychol Rev 2001;11:101-16.

10 Harris PA, Taylor R, Thielke R, et al. Research electronic data capture (REDCap)--a metadata-driven methodology and workflow process for providing translational research informatics support. J Biomed Inform 2009;42:377-81. 
11 Costa PT, McCrae RR. Domains and facets: hierarchical personality assessment using the revised Neo personality inventory. $J$ Pers Assess 1995;64:21-50.

12 McCrae RR, Costa PT, Martin TA. The NEO-PI-3: a more readable revised Neo personality inventory. J Pers Assess 2005;84:261-70.

13 Pilowsky I. Dimensions of hypochondriasis. Br J Psychiatry 1967;113:89-93.

14 Fink $\mathrm{P}$, Ewald $\mathrm{H}$, Jensen $\mathrm{J}$, et al. Screening for somatization and hypochondriasis in primary care and neurological in-patients: a seven-item scale for hypochondriasis and somatization. $J$ Psychosom Res 1999;46:261-73.

15 Pejtersen JH, Kristensen TS, Borg V, et al. The second version of the Copenhagen psychosocial questionnaire. Scand J Public Health 2010;38:8-24.
16 Michielsen HJ, De Vries J, Van Heck GL. Psychometric qualities of a brief self-rated fatigue measure: the fatigue assessment scale. $J$ Psychosom Res 2003;54:345-52.

17 Derogatis LR, Melisaratos N. The brief symptom inventory: an introductory report. Psychol Med 1983;13:595-605.

18 Olsen LR, Jensen DV, Noerholm V, et al. The internal and external validity of the major depression inventory in measuring severity of depressive states. Psychol Med 2003;33:351-6.

19 Schmidt M, Pedersen L, Sørensen HT. The Danish civil registration system as a tool in epidemiology. Eur J Epidemiol 2014;29:541-9.

20 [The health of the Danes 2017]: Danish Health Authority 2018.

21 Rådman L, Nilsagård Y, Jakobsson $\mathrm{K}$, et al. Electrical injury in relation to voltage, "no-let-go" phenomenon, symptoms and perceived safety culture: a survey of Swedish male electricians. Int Arch Occup Environ Health 2016;89:261-70. 